\title{
J. L. Austin, o realismo de 0xford e a epistemologia: uma releitura de 0ther Minds
}

\section{J. L. Austin, Oxford realism and epistemology: a re-reading of Other Minds}

\section{Sofia Miguens*}

Universidade do Porto, Porto, Portugal

\section{Resumo}

Este artigo propõe uma releitura do artigo Other Minds de J. L. Austin, um exemplo clássico e central do realismo de Oxford, que é hoje exponenciado por autores tão distintos entre si como John McDowell, Timothy Williamson, M. G. F. Martin, Paul Snowdon ou Charles Travis. Um objectivo da leitura é pôr em relevo algumas características da abordagem das questões epistemológicas no seio dessa corrente. Começo por contextualizar o estatuto da investigação epistemológica num quadro de filosofia da linguagem comum. Segue-se uma análise do artigo Other Minds em cinco passos. Finalmente exploro a aplicação ao problema das outras mentes das considerações performativas sobre conhecimento desenvolvidas ao longo do artigo, focando em particular o caso do testemunho.

Palavras-chave: J. L. Austin. Epistemologia. Realismo de Oxford. Outras mentes. Testemunho.

* SM: Doutora em filosofia, e-mail: smoraismiguens@gmail.com 


\section{Abstract}

In this article I offer a close reading of J. L. Austin's Other Minds. Other Minds is a classical and central exemple of Oxford realism, some current representatives of which are John McDowell, Timothy Williamson, M. G.F. Martin, Paul Snowdon and Charles Travis. One main aim of the proposed close reading is to identify some features of the approach to epistemological questions within Oxford realism. I start with observations regarding the status of epistemological investigations in the context of ordinary language philosophy. An analysis of "Other Minds" in five steps follows. I end by exploring the application of the performative approach to knowledge to the problem of other minds, giving particular attention to the case of testimony.

Keywords: J. L. Austin. Epistemology. Oxford realism. Other minds. Testimony.

\section{Introdução ${ }^{1}$}

O propósito deste artigo é levar a cabo uma releitura do artigo Other Minds do filósofo inglês J. L. Austin (1911-1960). O artigo foi escrito em 1946 - Austin viveria mais catorze anos - e é, para algumas pessoas interessadas em história da filosofia do século $\mathrm{XX}$, um dos mais importantes artigos de filosofia do século, comparável sob essa perspectiva apenas, por exemplo, a Two Dogmas of Empiricism de W. V. Quine ${ }^{2}$. O foco da minha análise é epistemológico. As principais

1 Este texto teve origem na 3a Sessão do Ciclo Austin's Revolution and Its Impact on Philosophy of Language organizado por Eduardo Marchesan no Instituto de Filosofia da Universidade do Porto, em 2015/2016. A sessão foi precedida pelas conferências de François Récanati (Sessão 1, 15 dezembro de 2015, Three types of act) e Charles Travis (Sessão 2, 22 de fevereiro, April in Pittsburgh - all about Wirklichkeit). 0 Ciclo insere-se na participação do Mind, Language and Action Group (MLAG) na Rede PloCo do CNRS ("Ordinary Language Philosophy and ordinary conceptions in the social sciences"). Participam na rede grupos de investigação das Universidades de Paris (Paris I - Panthéon-Sorbonne), Roma (La Sapienza), Porto (MLAG - Instituto de Filosofia), Boston (Tufts) e Baltimore (Johns Hopkins). 0 coordenador principal da rede em França é Bruno Ambroise (CNRS).

2 Era esta a opinião de Burton Dreben, filósofo de Harvard que muito influenciou a leitura da história da filosofia do século XX (cf. Gustafsson \& Sorli 2011, p. 20). Ao contrário de colegas seus de departamento tais como H. Putnam ou W. V. Quine, Dreben não alcançou uma reputação internacional alargada. A sua influência prática foi no entanto enorme. 0 ensino

Rev. Filos., Aurora, Curitiba, v. 28, n. 44, p. 653-686, maio/ago. 2016 
incursões de Austin nas questões epistemológicas (incluindo nas questões epistemológicas a questão da percepção) têm lugar em Other Minds e Sense and Sensibilia (1962). No seu conjunto representam uma alternativa à forma céptica, seja cartesiana ou empirista, de considerar as questões do conhecimento e são um exemplo central do chamado "realismo de Oxford", que se estende desde autores do início do século XX como J. Cook Wilson e H. A. Pritchard até autores actuais como J. McDowell, T. Williamson, M. G. F. Martin, P. Snowdon ou C. Travis ${ }^{3}$. A releitura que proponho aqui, sendo de foco epistemológico, pressupõe - ou numa reconstrução ideal erguer-se-ia sobre - as propostas de Austin acerca de acto e de verdade que foram objecto das análises recentes, mais directamente metafísicas, de François Récanati e Charles Travis ${ }^{4}$.

\section{0 contexto}

Other Minds foi originalmente uma apresentação num simpósio sobre Outras Mentes, em torno de John Wisdom (1904-1993), Professor em Cambridge. O simpósio teve lugar numa Joint Session da Aristotelian Society e da Mind Association, tal como estas acontecem ainda hoje, setenta anos depois. Além do próprio Wisdom, participaram no simpósio J. L. Austin e A. J. Ayer. Os textos foram publicado nos Proceedings of the Aristotelian Society (Supplementary v. 20: 148-187). Posteriormente Other Minds foi incluído nos Philosophical Papers de Austin (1961, 1aㅡ ed, p. 76-116).

de Dreben esteve nomeadamente na origem de toda uma escola de interpretação no seio da filosofia analítica actual, exponenciada por nomes como Warren Goldfard, Thomas Ricketts, Joan Weiner, Juliet Floyd, James Conant e outros.

3 Cf. Guy Longworth 2015: «His work on knowledge and perception places him in a broad tradition of "Oxford Realism", running from Cook Wilson and Harold Arthur Prichard through to J. M. Hinton, M. G. F. Martin, John McDowell, Paul Snowdon, Charles Travis, and Timothy Williamson». Para uma análise do realismo de 0xford articulada em torno das questões da linguagem, do conhecimento e da percepção cf. Travis e Kalderon 2013.

4 Refiro-me não apenas às conferências de François Récanati e de Charles Travis que precederam no Porto, a conferência que deu origem ao presente artigo mas também às participações dos dois autores noutras atividades da Rede $\mathrm{PloCo}$, nomeadamente a Conferência J. L. Austin's Philosophy Today (0xford, 4-5 setembro de 2015). 
J. L. Austin e L. Wittgenstein são os representantes centrais da chamada filosofia da linguagem comum ${ }^{5}$. No entanto, ao contrário do que aconteceu com Wittgenstein, quando Austin morreu a sua reputação apagou-se, ou pelo menos diminuiu. $\mathrm{O}$ seu nome tornou-se uma referência lateral na teoria dos actos de fala, que seria supostamente melhor representada por John Searle ${ }^{6}$. Mas essa é uma má imagem de Austin. Como veremos, o carácter específico da discussão epistemológica em Other Minds põe em causa uma certa caricatura da filosofia da linguagem comum, tal como esta seria precisamente representada e praticada por Austin, e que não é rara no seio dos próprios praticantes da tradição analítica. A ideia seria que os filósofos da linguagem comum se limitam a uma análise linguística preciosista, a fazer classificações minuciosas, cujo propósito se esgota meramente em fazê-las. A substância filosófica dos temas tratados seria, assim, indiferente, ou quase nula. A realidade é muito diferente. É certo que a filosofia da linguagem comum envolve uma concepção do método da filosofia que não se identifica nem com o naturalismo, nem com apelos à intuição, nem com o uso de regimentação lógica e, portanto, é metodologicamente divergente das tendências hoje dominantes na filosofia analítica. Mas o que está em causa, metodologicamente, é bem diferente de uma análise preciosista e estéril: o critério What do we say when...? (O que dizemos quando...?) da filosofia austiniana é uma forma de chegar às concepções em uso, i.e. ao pensamento e à linguagem em acto. É daí que se parte (não discutirei neste momento o ponto de chegada.) De qualquer forma, em termos de propostas substanciais, não há propriamente um vazio ou uma redução da atenção à linguagem. Na verdade não é, sequer, a linguagem per se que é o objecto dos filósofos da linguagem comum: a filosofia da linguagem comum não é linguística, nem é sobre linguagem, dizer "linguagem comum" marca o método, não o tópico.

\footnotetext{
Para uma abordagem da filosofia da linguagem comum, cf. Miguens, 2009.

6 Eu própria já dei por mim várias vezes, ao ensinar filosofia da linguagem, apresentando J. L. Austin dizendo apenas que ele "distingue enunciados constativos de enunciados performativos" escreve How to Do Things with Words e passando à frente, começando imediatamente a falar sobre o trabalho de John Searle e a sua taxonomia dos actos de fala. Também J. Habermas é um exemplo deste tipo de procedimento, por exemplo na Teoria da Acção Comunicacional (1981). J. Searle, que foi aluno de Austin em $0 x f o r d$, tem alguma responsabilidade aqui.
} 
Os tópicos da filosofia da linguagem comum são os expectáveis em filosofia - se trata, por exemplo, de epistemologia - estão em causa tópicos como o cepticismo, a percepção ou o testemunho. Não seria, aliás, difícil desenhar um campo lato de propostas positivas propriamente epistemológicas da filosofia da linguagem comum ${ }^{7}$.

Um dos tópicos epistemológicos presentes em Other Minds, e a que prestarei particular atenção no final da análise que se segue, é o testemunho. As observações de Austin sobre testemunho aparecem no contexto da abordagem do problema das outras mentes, o qual é, obviamente, o foco central do artigo. Não é de todo indiferente que a questão do testemunho apareça em Austin no seio do seu tratamento do problema das outras mentes. Pense-se no contraste com o contexto contemporâneo, frequentemente, próximo da ciência cognitiva. Neste contexto o problema das outras mentes, formulado por meio de questões tais como "Como sei que as outras pessoas têm um interior mental? Como eu sei que não são zombies?", nos conduz naturalmente a algo de muito diferente, por exemplo, ao papel dos chamados neurónios espelho nas nossas habilidades de mindreading. Há, no entanto, algo de excessivamente simplista em colocar o problema das outras mentes directamente em termos de mecanismos cognitivos operantes na atribuição de um interior mental a outros sistemas no mundo. Uma razão pela qual essas abordagens tendem a ser simplistas é o facto de desconsiderarem a linguagem. Ora a abordagem do problema em Other Minds, e no Simpósio de 1946 em geral, situa-se claramente num contexto de atenção à linguagem.

O problema é introduzido com as seguintes citações de Proust, em sua célebre obra intitulada Em busca do tempo perdido:

Voltando a Françoise [...] Se então na minha fúria perante a ideia de que ela teria piedade de mim, eu tentasse fingir que pelo contrário tinha

7 Este é aliás um aspecto em que uma comparação entre os dois representantes centrais da filosofia da linguagem comum, L. Wittgenstein e J. L. Austin, se revela particularmente interessante e tem constituído objeto de atenção no seio da Rede do CNRS atrás referida. Para uma abordagem wittgensteiniana do problema das outras mentes que será aqui tratado em Austin, cf. Miguens (no prelo), "The ever-present temptation of answering the skeptic - John McDowell's and Stanley Cavell's wittgensteinianism". 
tido um claro sucesso, as minhas mentiras embatiam na muralha da sua respeitadora mas óbvia descrença. Porque ela sabia a verdade.

[...] Foi ela quem primeiro me deu a ideia de que uma pessoa não está lá, imóvel e clara, perante os nossos olhos (como eu tinha pensado), com os seus méritos, os seus defeitos, os seus planos, as suas intenções quanto a nós expostas à sua superfície, como um jardim para o qual olhamos através de uma grade, com todos os limites dispostos perante o nosso olhar, mas é uma sombra, que nunca conseguimos penetrar, da qual nunca pode haver conhecimento directo, com respeito à qual formamos incontáveis crenças, baseadas nas suas palavras e por vezes nos seus actos, embora nem as palavras nem os actos nos possam dar senão informação inadequada e contraditória, uma sombra por trás da qual podemos imaginar, de forma alternada, que arde a chama do ódio e do amor ${ }^{8}$.

É John Wisdom quem introduz as citações, usando-as como epígrafes ao seu artigo de abertura do simpósio. Em Other Minds Austin retoma várias das expressões e exemplos de Wisdom. No que se segue estarão em causa os seus propósitos no artigo e no debate. Porque as etiquetas e classificações do jargão da epistemologia, por vezes, podem ser úteis e porque podem, neste caso, nos ajudar a dirigir o olhar para as teses características do realismo de Oxford, avanço desde já alguns traços do perfil de Austin como epistemólogo9.

Austin defende que o conhecimento é uma forma básica de apreensão de como as coisas são no nosso ambiente e não um híbrido de crenças mais cláusulas adicionais - trata-se, noutras palavras, daquilo a que hoje se chama knowledge-first epistemology, com a esperada oposição a análises do tipo da análise de Gettier (a análise do conhecimento proposicional em termos de condições necessárias e suficientes). Saber (knowing) não é uma variedade de acreditar (believing), nem é uma combinação de algo de mental com algo de não-mental. A isto Austin acrescenta a ideia segundo a qual o conhecimento surge do exercício bem sucedido de capacidades de juízo em circunstâncias propícias ${ }^{10}$. Ora se essas capacidades

8 Tradução minha, a partir do texto do Simpósio de 1946 (p. 122).

9 Farei para isso apelo ao filósofo inglês Guy Longworth (Longworth, 2015), bem como a Travis \& Kalderon (2013).

${ }_{10}$ Como diz Guy Longworth (2015), o conhecimento surge «through a combination of acumen (o termo significa a capacidade de fazer juízos acertados e tomar decisões rápidas, S.M.) and opportunity». 
podem sem dúvida falhar, tal não invalida o facto de elas serem usualmente bem sucedidas: é sempre possível julgar incorrectamente, mas há casos nos quais os nossos juízos sobre o ambiente são perfeitamente seguros. Uma consequência conjunta das posições acima é a oposição ao fundacionalismo, nomeadamente ao tipo de fundacionalismo que sugere como proposições básicas, fundacionais e indubitáveis os sense statements (enunciados acerca de "sensações") ${ }^{11}$ : as nossas capacidades de juízo, quando em exercício, podem misfire (funcionar mal) quanto a qualquer assunto, até mesmo quando aplicadas ao nosso interior, i.e. a pensamentos, sentimentos ou sensações.

Quanto à percepção, Austin defende um realismo directo, sendo por vezes considerado um predecessor do hoje chamado disjuntivismo em filosofia da percepção ${ }^{12}$. Ele próprio nunca se anuncia de forma tão simplista - e tem aliás grandes dificuldades com um termo metafísico como "realismo". Isto é particularmente notório em Sense and Sensibilia. É indesmentível pelo menos, no entanto, que Austin se opõe a qualquer apelo a sense data, e que rejeita o Argumento da Ilusão. Sense and Sensibilia é, aliás em grande medida, uma descontrução do argumento da Ilusão, que Austin vê como um "dispositivo" que serviria para nos fazer aceitar sense data quando pensamos sobre a percepção ${ }^{13}$. Quanto a outras mentes, Austin defende uma posição "não-inferencialista".

${ }^{11}$ Este era representado no tempo de Austin por exemplo por A. J. Ayer, outro dos participantes no simpósio, e um representante do Positivismo Lógico no Reino Unido.

12 Cf. Soteriou 2013.

13 Tim Crane e Craig French, no seu artigo da Stanford Encyclopedia intitulado "The problem of perception" analisam da seguinte forma a estrutura do Argumento da llusão (cuja conclusão é que o realismo ingénuo, ou realismo directo, é falso): «i. When one is subject to an illusion, it seems to one that something has a quality, $F$, which the real ordinary object supposedly being perceived does not actually have. ii. When it seems to one that something has a quality, $F$, then there is something of which one is aware which does have this quality. iii. Since the real object in question is, by hypothesis, not- $F$, then it follows that in cases of illusion, either one is not aware of the real object after all, or if one is, one is aware of it only "indirectly" and not in the direct, unmediated way in which we normally take ourselves to be aware of objects. iv. There is no non-arbitrary way of distinguishing, from the point of view of the subject of an experience, between the phenomenology of perception and illusion (...) v. Therefore, there is no reason to suppose that even in the case of genuine perception one is directly or immediately aware of ordinary objects. vi. Therefore our normal view about what perceiving is — sometimes called "naïve realism" or "direct realism" — is false. So perception cannot be what we normally think it is». Aquilo que a percepção não pode ser e que pensávamos ('ingenuamente') ser é nomeado por French e Crane no mesmo artigo como 'openness to the world' (abertura ao mundo). 
Finalmente é um crítico do intelectualismo da posição individualista ${ }^{14}$ e reducionista ${ }^{15}$ sobre testemunho: o conhecimento por testemunho pode ser conhecimento em segunda mão, mas o conhecimento em segunda mão não é conhecimento de segunda categoria ${ }^{16}$. A ocorrência de testemunho de outro indivíduo muda completamente as coisas em termos de conhecimento, e isto interessa Austin particularmente.

No que se segue passarei por todos os pontos acima, mais em concreto, seguindo o texto de Other Minds. Queria apenas, para terminar esta contextualização da análise do artigo, esclarecer alguns pontos quanto a testemunho. O termo testemunho aparece na linguagem epistemológica quando se identifica fontes de crenças, e significa simplesmente vir a saber alguma coisa porque alguém nos diz que as coisas são de uma certa maneira. Trata-se aqui não apenas das situações sociais exemplares de testemunho, tais como prestar declarações num tribunal (situações de "alta exigência epistémica", de testemunho formal), mas de situações tão simples e quotidianas como aquela em que alguém (por exemplo eu própria, no contexto de uma aula) afirma que "Mendeleev, Lenine e Pavlov estudaram, todos eles, na Universidade de São Petersburgo" e a audiência forma ou fixa essa crença, e passa a pensar que as coisas são dessa forma. Saber por testemunho é vir a saber alguma coisa por intermédio de alguém, por contraste com abrir os olhos e ver. O testemunho contrasta assim com a percepção, que é a fonte de conhecimento paradigmática para os empiristas e que é, tipicamente, o foco de uma abordagem individualista do conhecimento. Em Other Minds Austin está interessado nesses dois componentes fundamentais da nossa forma de pensar que são percepcionar e vir a saber alguma coisa por intermédio de alguém que nos fala. A grande diferença será: "The goldfinch, the material object, is, as we insisted above, uninscribed and mute: but the man speaks" (p. 113) ${ }^{17}$.

${ }^{14}$ De acordo com a perspectiva individualista o conhecimento é prosseguido por agentes cognitivos isolados.

150 reducionismo acerca de testemunho reduz a justificação das crenças por testemunho às credenciais epistémicas de outras fontes de crença e conhecimento, tais como a percepção, a memória e a inferência.

16 Retomo aqui os termos de 0'Brien (2013: 120).

17 Utilizarei sempre daqui em diante a paginação dos Philosophical Papers de Austin. Em geral citarei as passagens do original inglês. Algumas vezes, por uma questão de expressividade e de apoio para aquilo que estou a procurar dizer em português, traduzo passagens breves e inisiro-as no texto. 
Os autores que servem hoje de referência na epistemologia do testemunho são, entre outros, C. A. J. Coady, Miranda Fricker ou Martin Kutsch. Neste artigo falarei, mais à frente, de Benjamin McMyler, dada a sua interpretação recente das observações de Austin sobre testemunho em Other Minds. Talvez seja, no entanto, mais simples olhar para a epistemologia do testemunho de um ponto de vista histórico. A epistemologia do testemunho é uma parte da teoria do conhecimento historicamente marcada pelas posições de David Hume, que a tratou (nomeadamente na Secção X, intitulada "Dos Milagres", da Investigação sobre o Entendimento Humano) em torno da questão dos milagres e das nossas razões para acreditar ou não acreditar em relatos de milagres. $\mathrm{O}$ choque clássico das posições de Hume e de um outro filósofo escocês, o fundador da chamada common sense philosophy, Thomas Reid, é emblemático, ainda hoje, da forma como se desenha o campo de controvérsia na epistemologia do testemunho. De acordo com o chamado reducionismo individualista de Hume, precisamos ter evidência de que quem nos oferece um determinado testemunho é fiável antes de acreditarmos no seu testemunho. Noutras palavras: sou eu que avalio se tenho justificação para acreditar no que alguém me diz, nomeadamente considerando se essa pessoa tem um "bom registo" quanto a falar verdade ${ }^{18}$. Sou eu que recolho evidência e que decido se acredito ou não acredito no seu testemunho. Segundo Reid o que se passa é bem diferente: antes de não acreditar no que alguém me diz preciso de evidência contrária à fiabilidade dessa pessoa. A nossa posição by default perante os outros é de confiança (trust). Ninguém nega que mentiras, insinceridade e embustes vários são o pão nosso de cada dia nas interacções linguísticas e psicológicas dos humanos - elas só podem, no entanto, existir precisamente sobre um pano de fundo de confiança (confiar significa, aqui, atribuir autoridade ao falante, acreditar nas outras pessoas).

18 Retomo aqui a expressão de Dan 0'Brien (0'Brien 2013). 


\section{Análise de Other Minds}

\section{A questão epistemológica elementar e os dois exemplos iniciais}

No início de Other Minds (p. 76) anuncia-se o pretexto prático da discussão: John Wisdom escreveu uma série de artigos sobre outras mentes, e lá colocou a questão How do we know that another man is angry? A sua questão geral de partida é portanto aquela a que podemos chamar a questão epistemológica elementar ("Como é que sabes que p?"), aplicada às outras mentes. Chamo questão epistemológica elementar à interrogação "Como é que sabes?" anteposta a qualquer pretensão de conhecimento. A questão epistemológica elementar é colocada quando, por exemplo, eu digo "Está a chover" e alguém pergunta "Como é que sabes que está a chover?", ou quando eu digo " $7+5=12$ " e alguém pergunta “Como é que sabes que $7+5=12$ ?". Aqui ela é aplicada a saber que está um pintassilgo no jardim (How do you know that there is a goldfinch in the garden?) e saber que outra pessoa está zangada (How do you know that another man is angry?). É esta última questão que é introduzida em primeiro lugar no artigo - é a questão que Wisdom coloca, depois das citações de Proust, que usa como epígrafe e que recordei atrás. Já a questão How do you know that there is a goldfinch in the garden? é introduzida como um exemplo particularmente simples de statement of a particular, current, empirical fact (enunciação de um facto particular, comum, empírico). E Austin continua a glosar Wisdom: Será que sabemos que outra pessoa está zangada da mesma maneira como sabemos que uma chaleira está a ferver, ou que há uma festa na porta ao lado, ou qual é o peso da lanugem de cardo? "Mr. Wisdom's method is to go on to ask: Is it like the way in which we know that a kettle is boiling, or that there is a teaparty next door, or the weight of the thistledown?" (p. 76).

O que, exactamente acontece, em ocasiões específicas, quando se pergunta às pessoas Como é que sabes que p? - é isto que Austin vai considerar no artigo. O que acontece, por exemplo, quando se pergunta às pessoas How do you know that there is a goldfinch in a garden? How do you know that another man is angry? (p. 77). Nas palavras de Austin ficamos expostos às questões Do you know there is? Do you know he is? How do 
you know? E podemos por exemplo responder: No, but I think there is e No, but I believe he is.

A primeira coisa que Austin quer estabelecer aqui é a existência de uma diferença entre knowing (saber) e believing (acreditar, achar, pensar que). Nós perguntamos (1) How do you know that p? e (2) Why do you believe that $p$ ? (ou, em português: Como é que sabes que p? e Porque é que acreditas que $p$ ?) Aparentemente nunca perguntamos Why do you know that $p$ ? nem How do you believe that $p$ ? (i.e. não perguntamos Porque é que sabes que $p$ ? Nem Como é que acreditas que p?). Quanto a 1, diz Austin, a implicação de How do you know that $p$ ? é que talvez não saibas. Quanto a 2, a implicação de Why do you believe that $p$ ? é que talvez não devesses acreditar naquilo em que acreditas. De qualquer forma:

...saying 'I know' ...is not saying 'I have performed a specially striking feat of cognition, superior, in the same scale as believing and being sure, even to being quite sure': for there is nothing in that scale superior to being quite sure. (p. 99).

Então, o que é saber alguma coisa, ter conhecimento, se não é um espantoso feito de cognição, superior a acreditar ou a ter a certeza? É o que se verá no resto do artigo. Continuando com os exemplos de pássaros, o exemplo é agora There is a bittern at the bottom of the garden (Está um abetouro ${ }^{19}$ no fundo do jardim) (p. 79). Se alguém me pergunta Como é que sabes que está um abetouro no fundo do jardim? a minha resposta pode ter várias formas. Posso dizer (p. 79):

1. "Cresci junto aos pântanos / pauis"

2. "Ouvi-o"

3. "O guardador disse que lá havia um"

4. "Pelo seu arrulhar"

5. "Pelo ruído do arrulhar"

6. "Porque está a arrulhar"

19 Botaurus pinnatus, ou garça-vaqueira. 
As três primeiras são respostas a How do you know?, as três seguintes são respostas a How can you tell?. A implicação é que para reconhecer uma dessas aves (um abetouro) eu devo: 1) ter sido treinado num ambiente em que me poderia ter familiarizado com essas aves; 2) ter tido uma certa oportunidade no caso actual; 3) ter aprendido a reconhecer os abetouros; 4 ) ter sido bem sucedido a identificar uma ave como um abetouro. Os pontos 1 e 3 querem dizer que a minha experiência passada deve ter sido de certo tipo, 2 e 4 têm a ver com quão bem nós estamos a fazê-lo no caso actual, quão bem sucedido está a ser o exercício de um certo esforço, ou perícia.

Por vezes chama-se às respostas à questão Como é que sabes? as nossas "razões para saber alguma coisa", diz Austin. É ao considerar razões que nós damos para sabermos alguma coisa que a questão do testemunho surge no artigo. Uma classe especial e importante das razões que nós damos quando dizemos saber alguma coisa, é citarmos autoridades: "How do you know the election is today? I read it in The Times - How do you know the Persians were defeated at Marathon? Herodotus says it" (p. 81-82).

Como Austin nota," The statement of an authority makes me aware of something, enables me to know something, which I shouldn't otherwise have known. It is a source of knowledge" (p. 82).

Claro que este tipo de conhecimento é susceptível de estar errado, dada a não fiabilidade do testemunho humano, os enviesamentos, a mentira, o exagero, etc. Mas o facto é que a ocorrência de testemunho humano altera radicalmente a nossa situação epistemológica (p. 82). É fundamental ao falarmos, ao usarmos linguagem, nós termos o direito de confiar nos outros: "Believing other people, accepting testimony, is the, or one main, point of talking" (p. 82).

Não atuamos em jogos de competição excepto se acreditarmos que o nosso adversário está a tentar ganhar. Se ele não estiver a tentar ganhar, não se tratará de um jogo de competição, mas de alguma coisa diferente. Da mesma forma "we don't talk with people except in the faith that they are trying to convey information" (p. 82-83). 


\section{Como disputar ou contestar o que eu digo quando eu digo como é que sei}

Para dizer como sei que está um pintassilgo no jardim, menciono as características da situação permitindo o reconhecimento de algo como algo (Como é que sabes que é um pintassilgo? - Pela cabecinha vermelha). E alguém pode objectar: mas os pintassilgos não têm cabeças vermelhas. Ou então: mas isso não é um pintassilgo - é.... (outro pássaro qualquer). Ou então: mas isso não é suficiente, há vários pássaros com cabeças vermelhas, só por isso não podes saber que é um pintassilgo. Noutras palavras, para pôr em causa aquilo que eu digo presume-se que eu sou incapaz de reconhecer P como P (pintassilgos, neste caso). Mas se alguém diz que a cabeça vermelha não é suficiente, então deve ter em mente uma falha específica qualquer: deve estar pensando por exemplo que as manchas nos olhos também deveriam estar presentes. Seria tolo dizer simplesmente "isso não é suficiente" e mais nada. Por outro lado, dizer que eu sei que aquilo é um pintassilgo, que eu sou de facto capaz de dizer que é um pintassilgo, quer dizer, apenas, que para os presentes propósitos e na presente situação eu sei que é um pintassilgo: "Enough is enough - it is not everything. It does not mean, for instance, to show that it is not a stuffed goldfinch" (p. 84).

Dizer que é suficiente para os presentes propósitos e na presente situação significa que para os presentes propósitos não há uma alternativa pertinente. Não significa, por exemplo, que é suficiente para estabelecer definitivamente que não se trata de um pintassilgo empalhado. Saber para os presentes propósitos é o que é (is what it is), e não é muitas outras coisas (and is not many other things). Eis a análise desta passagem feita por Guy Longworth (2015):

One way of reading Austin here is as allowing that we can know that this is a goldfinch, even though we know that if it's a stuffed goldfinch, then it is not a goldfinch, and we don't know that it isn't a stuffed goldfinch. We are entitled - either in general, or in circumstances of this sort - to assume or rely upon its not being a stuffed goldfinch, even though that is something we can't rule out and don't know. 
Repare-se no que foi feito até agora. Austin está a analisar o que se passa quando eu digo que sei alguma coisa (por exemplo, que está um pintassilgo no jardim). Eu posso ser tomado como claiming, being able to prove (tendo uma pretensão, sendo capaz de provar) que está um pintassilgo no jardim. E o que ele está a fazer é considerar as questões normalmente levantadas, em contextos correntes, pela questão Como é que sabes? para desafiar a minha pretensão. E chama a atenção para o facto de nesses contextos nós contarmos como sabendo que alguma coisa é um pintassilgo mesmo se sabemos que, se é um pintassilgo empalhado, então não é um pintassilgo, e nós não sabemos que aquilo não é um pintassilgo empalhado. O que isto significa é que até agora (nas palavras do próprio Austin no artigo) não foram disputados (com essas questões) os meus factos, nem foram disputadas as minhas credenciais como agente cognitivo. Mas, diz Austin, os filósofos dão um passo a mais (pensemos em Descartes): os filósofos preocupam-se com a realidade e com ter a certeza. E perguntam: como é que sabes que é um pintassilgo real, um verdadeiro pintassilgo? Como é que sabes que não estás a dormir e a sonhar? Ora isto já é disputar os meus factos e as minhas credenciais como agente cognitivo, diz Austin.

\section{Realidade, sureness (estar seguro) e certainty (ter a certeza)}

Nos pontos seguintes do artigo (os pontos 1. Reality e 2. Sureness and certainty) começamos a entrar em território austiniano mais conhecido, incluindo o território daquilo a que hoje se chamaria a filosofia da percepção. Encontramos, assim, temas classicamente associados a Austin: a contestação dos sense data, a contestação do cepticismo, a defesa do realismo directo, as ironias quanto à noção ser real.

Austin faz notar que perguntar Como sabes que está um pintassilgo no jardim? é muito diferente de perguntar Como sabes que é um verdadeiro pintassilgo, ou Como sabes que é um pintassilgo real? Se tu me perguntas, quando eu experiencio a vara dobrada de Sense and 
Sensibilia ${ }^{20}$, como eu sei que é uma vara real, ou que ela está realmente dobrada, tu estás a questionar as minhas credenciais ou os meus factos de uma maneira especial.

O que Austin quer dizer é o seguinte: uma coisa é admitir que a minha experiência neste momento, ou o objecto que experiencio, pode ser abnormal, ou phoney (anormal, estranho, com qualquer coisa de forjado ou fingido). Pode haver sonho e delírio. Pode-se estar sob efeito de drogas. Pode haver coisas empalhadas, coisas virtuais, coisas alucinadas. Pode haver espelhos, miragens, imagens, efeitos de luz ${ }^{21}$. Muito bem, mas as dúvidas acerca destas coisas podem ser afastadas por meio de procedimentos reconhecidos como apropriados para cada tipo de caso. Já quanto a distinguir a realidade da não-realidade de um $x$ qualquer, o que havemos de fazer, pergunta? (p. 87) O que quer dizer "X é um verdadeiro $C$ " ?

What are you suggesting? - Pergunta Austin. O que é suposto eu fazer para provar que uma coisa é real? Que palavra profunda é essa, ser real, ser um verdadeiro $x$ ? Se insistirmos em que o desafio seja especificado encontraremos para cada caso uma palavra "menos fatal" do que a palavra "real", observa Austin: o pintassilgo pode ser empalhado, mas não estamos a sugerir que seja uma miragem; o oásis pode ser uma miragem, mas não estamos a sugerir que seja empalhado. "The goldfinch might be stuffed but there is no suggestion that it's a mirage, the oasis might be a mirage, but there is no suggestion that it is stuffed [...]"(p. 87).

Being sure it is real is no more proof against miracles or outrages of nature than anything else is, or sub specie humanitatis, can be. If we've made sure it's a golfinch, and a real goldfinch, and then in the future it does something outrageous (explodes, quotes Mrs. Woolf, or what not),

20 Um dos exemplos centrais de (suposta) ilusão em Sense and Sensibilia é o clássico caso da vara recta mergulhada na água, que, dado o fenómeno da refracção, é vista como curva.

${ }^{21}$ Todos estes são exemplos de Sense and Sensibilia. A lista de Austin inclui coisas que parecem ser 0 que não são, coisas que não são o que parecem, em suma, os exemplos usualmente avançados de "aparências enganosas". A sua forma de conceber a percepção irá no entanto levá-lo a desconstruir e rejeitar a própria expressão "aparências enganosas", na medida em que esta presume que as aparências nos dizem alguma coisa que pode estar em contradição com alguma outra coisa. Ora tais "vestes lógicas" não pertencem segundo Austin aos apareceres perceptivos, que são "mudos", mas apenas a afazeres de criaturas linguísticas, como os juízos. 
we don't say we were wrong to say it was a goldfinh, we don't know what to say (p. 88).

Traduzo o fim deste ponto: se o pintassilgo, o qual reconheci como pintassilgo, explodir, ou começar a citar Virginia Woolf, eu não vou dizer que estava enganado e que afinal não era um pintassilgo; eu simplesmente não sei o que dizer. Fico sem palavras. É um erro pensar que a linguagem pode ser preditiva, de uma forma tal que o futuro prove que a linguagem estava errada, afirma Austin: "aquilo que o futuro pode (sempre) fazer é fazer-nos rever as nossas ideias sobre pintassilgos, pintassilgos reais, ou o que quer que seja" (p. 89).

A outra forma de pôr em questão os meus factos e as minhas credenciais é diferente da pergunta acerca de algo ser ou não ser real, e vai ter a Mr. Wisdom e ao nosso conhecimento das nossas sensações. Também aqui estamos em pleno território de Sense and Sensibilia. O que está sob discussão é a ideia segundo a qual uma pessoa não pode estar errada acerca dos seus próprios sense statements. Quanta filosofia se imiscui aqui, comenta Austin! (p. 90) - a maçã de Berkeley, the tree in the quad. Diz-se: a não ser que eu esteja a mentir, eu não posso estar enganado quando digo "I'm in pain' ou 'Here is something that looks red to me now" (p. 91). É assim que o filósofo se retira do mundo em que todos vivemos, comenta Austin (p. 90). Nas páginas 91-93 o que Austin faz é descrever tastes e looks, indo atrás do que é estar certo, estar seguro, ter a certeza. Vou resumir bastante o que se passa, e fazer apelo a Guy Longworth, para discernir o propósito da discussão, que é afinal a discussão sobre o estatuto de aparências e "apareceres" que também se encontra em Sense and Sensibilia. Austin diz o seguinte: "Being certain' tends to indicate confidence in our memories and our past discernment, 'being sure' to indicate confidence in our current perception" (p. 93).

E segundo Longworth (2015): The following two passages are central to understanding Austin's views in this area:

Any description of a taste or sound or smell (or colour) or of a feeling, involves (is) saying that it is like one or some that we have experienced before: any descriptive word is classificatory, involves recognition and 
in that sense memory, and only when we use such words (or names or descriptions, which come down to the same) are we knowing anything, or believing anything. But memory and recognition are often uncertain and unreliable. (p. 92) 22

[...] sensa [the things we sense or perceive] are dumb, and only previous experience enables us to identify them. If we choose to say that they 'identify themselves' (and certainly 'recognizing' is not a highly voluntary act of ours), then it must be admitted that they share the birthright of all speakers, that of speaking unclearly and untruly. (p. 97)

Noutras palavras: Austin retoma aqui a célebre tese de Sense and Sensibilia, a tese do silêncio dos sentidos ${ }^{23}$. Os sentidos são mudos: não dizem verdades nem falsidades, simplesmente porque não falam. E é também por isso que não podem enganar-nos. Apenas exercícios de juízo (nossos, i.e. de criaturas linguísticas), em circunstâncias e contextos específicos, podem ser verdadeiros ou falsos. O propósito deflaccionista da argumentação de Sense and Sensibilia pode ser resumido em torno do clássico exemplo de ilusão da vara recta que, mergulhada na água, parece curva. Sim, a vara parece curva na água - há uma ilusão, diz-se, nós não vemos as coisas como elas são, a vara ela própria não pode ser curva e recta ao mesmo tempo, logo, a sua aparência é enganosa. O passo seguinte torna-se então possível: quando nós percepcionamos a vara (que é recta) como curva, estamos de facto a percepcionar alguma coisa, que não pode ser a vara; então, isso que percepcionamos quando percepcionamos a vara como curva são sense data; pelo menos deles temos absoluta certeza. Mas Austin quer, precisamente, evitar tais conclusões as quais ele considera extremas e injustificadas acerca da existência de "intermediários" na percepção - os sense data - a partir da mera ocorrência de experiências "enganosas". Por isso Austin pergunta: como exactamente deveria parecer uma vara recta quando mergulhada na água, dada a refracção, a não ser curva? A vara não parece curva a todos, quando olhamos para ela, imersa na água? Estaremos todos iludidos? Será uma

220 texto de G. Longworth inclui aqui as citações do texto de Austin. As páginas referem-se à edição dos Philosophical Papers que tenho estado a utilizar.

${ }^{23}$ Cf. Travis 2004, para uma análise influente. 
ilusão colectiva? Estaremos a ver coisas que não existem? A posição de Austin é que se trata de uma aparência totalmente objectiva e partilhável. Não explorarei aqui os tópicos de Sense and Sensibilia - basta recordar que Austin rejeita que o uso do Argumento da Ilusão a partir de casos de "aparências enganosas" nos obrigue a admitir as entidades puramente subjectivas que são os sense data. A razão fundamental para a rejeição do uso do Argumento da Ilusão é o facto de a ideia de aparências enganosas pressupôr que os sentidos nos "dizem alguma coisa" (ou, na passagem citada, que as coisas "se identificam a si próprias"), e isto é algo que Austin liminarmente rejeita.

\section{"If I know I can't be wrong"}

O ponto desta parte do artigo é que temos frequentemente razão para dizer que sabemos alguma coisa (tal como: está um pintassilgo no jardim), mesmo se subsequentemente viermos a verificar estar errados. Longworth (2015) nos previne:

He never quite endorses the condition. He admits at one point that its third person counterpart makes sense, but characterizes the sense it makes by appeal to a prohibition on saying "I know it is so, but I may be wrong" (p. 98).

Na verdade we are practically always liable to be mistaken (p. 98), é practicamente sempre possível que estejamos enganados, diz Austin. Mesmo assim, o melhor a fazer é ser cândidos quanto a esta vulnerabilidade, que não é assim tão onerosa na prática. $\mathrm{O}$ intelecto humano e os sentidos são inerentemente falíveis, mas isso não significa que sejam inveteradamente falíveis. As máquinas também são inerentemente capazes de se avariar, porém tal não significa que uma boa máquina o faça constantemente, e em cada caso. Usualmente ela funciona bem.

Onde é que Austin quer chegar? Em primeiro lugar, ele quer defender que dizer "Quando sabemos alguma coisa, não podemos estar enganados" faz sentido. Nós não andamos por aí a dizer "Eu sei que p, 
ah bom, mas posso estar enganado", tal como não andamos por aí a dizer "Eu prometo que te pago a minha dívida, mas fica já prevenido que posso falhar, não cumprir". You are prohibited from saying this, diz Austin. É certo que, diz Longworth (2015),

Like all other human capacities, human judgmental capacities are inherently limited and fallible. The capacities are inherently limited in that there are bound to exist cases with respect to which they are insufficiently reliable to give rise to knowledge. And they are inherently fallible in that, even in the most propitious circumstances, it is possible that their exercise is unsuccessful. (The risk of fallibility is liable to increase, of course, as the capacities approach the limits within which their application is reliable.) (Austin 1961, p. 90-97; Austin 1962: 104-131)

Mas, continua (Longworth 2015), "The fact that capacities that are essentially involved in the acquisition of knowledge are inherently limited and fallible is consistent with their operating successfully in a variety of circumstances so as to give rise to knowledge" (Austin 1961: 83-103; Austin 1962: 104-131).

E agora o próprio Austin:

If you are aware you might be mistaken, you ought not to say you know, just as, if you are aware you may break your word, you have no business to promise. But of course being aware that you may be mistaken doesn't mean merely being aware that you are a fallible human being: it means that you have some concrete reason to suppose that you might be mistaken in this case. Just as 'but I may fail' does not mean merely 'but I am a weak human being' (in which case it would be no more exciting that adding D.V.): it means that there is some concrete reason for me to suppose that I shall break my word. It is naturally always possible ('humanly' possible) that I may be mistaken, or may break my word, but that by itself is no bar against using the expressions ' $\mathrm{I} \mathrm{know}^{\prime}$ and 'I promise' as we in fact use them (p. 98).

É precisamente neste contexto e neste ponto do artigo que Austin propõe um paralelismo entre saber e prometer. Esse paralelismo é o ponto crucial das observações sobre testemunho em Other Minds. É nele que se opera o cruzamento da teoria dos actos de fala com a epistemologia. 
Comecemos com o acto de fala de prometer. Quando eu prometo ("I promise to do $A$ ") um passo novo tem lugar relativamente à mera expressão de uma intenção. Ao dizer ("I promise to do $A$ ") eu não estou apenas a anunciar a minha intenção: cumprindo o ritual de prometer, eu ligo-me com outrem, arriscando a minha reputação. Ora, o mesmo se passa quando eu digo "I know that p". De novo, não é que aconteça algo de "superior" ao ter a certeza. O que se passa é que quando eu digo "eu sei que p" eu dou a minha palavra aos outros, eu dou-lhes, ou transmito-lhes, a minha autoridade (para eles próprios virem a dizer que "Mendeleev, Lenine e Pavlov estudaram na Universidade de São Petersburgo").

Quando eu digo apenas "eu penso que..." ou "eu creio que ..." ninguém me pode pegar por isso. Mas se, por exemplo, eu te prometi alguma coisa, tu estás justificado a actuar com base nisso, escolhas ou não fazê-lo. Da mesmo forma, se alguém me diz que sabe alguma coisa, eu tenho o direito ( $I$ am entitled) de também dizer que sei, em segunda mão. O direito é transmissível, da mesma forma que outros tipos de autoridade são transmissíveis.

We all feel the very great difference between saing even "I am sure" and saying "I know": it is like the difference between saying even "I firmly and irrevocably intend" and saying "I promise" (p. 100).

Como se desafia o saber e o prometer? Pondo em causa que quem sabe, ou quem promete, esteja em posição para isso. Austin lembra que alguns filósofos têm tantas dúvidas sobre tanta coisa que diriam que eu nunca estou em posição de saber o que quer que seja. Talvez devessem então dizer também que eu nunca estou em posição de prometer algo, acrescenta. Em ambos os casos, a obsessão de não falhar nos restringiria totalmente os movimentos. Para Austin isto está errado em ambos os casos. Dizer que se sabe é fazer alguma coisa e, obviamente, fazer alguma coisa é, sempre, poder falhar. O ponto de Austin é que isso não nos impede, nem deve impedir-nos, de agir. Torna-se aqui extremamente claro que Austin é acima de tudo um filósofo da acção, e que o seu grande princípio acerca da acção é que se há acção, muita coisa pode sempre correr mal, há sempre a possibilidade de misfiring, 
missing, etc (i.e. se agimos, há sempre a possibilidade de maus funcionamentos, falhanços, acções abortadas). Mas nós estamos perfeitamente justificados, ainda assim, a agir, por exemplo dizendo que sabemos alguma coisa, ou prometendo alguma coisa.

Vejamos o que acontece no caso de as coisas correrem mal quando se sabe alguma coisa. Será este um caso semelhante ao caso de prometer? You're proved wrong, so you didn't know parece contrastar com You've failed to perform, although you did promise. "Provou-se que estavas errado, por isso não sabias que p" é aparentemente diferente de "Prometeste, mas não cumpriste". Mas o contraste é apenas aparente, defende Austin. O que está em causa em ambos os casos são circunstâncias apropriadas e a forma como as coisas correram. E é exactamente aqui que sugere a comparação entre os casos de performativos mais usualmente considerados na teoria dos actos de fala e o caso de I know:

In these 'ritual' cases, the approved case is one where in the appropriate circumstances, I say a certain formula: e.g. 'I do' when standing, unmarried or a widower, besides woman, unmarried or widow and not within the prohibited degrees of relationship, before clergyman, registrar, \&c., or 'I order' when I have the authority to, \&c. But now, if the situation transpires to have been in some way not orthodox (I was already married, It wasn't mine to give; I had no authority to order), then we tend to be rather hesitant about how to put it, as heaven was when the saint blessed the penguins. We call the man a bigamist, but his second marriage was not a marriage, is null and void (a useful formula in many cases for avoiding saying either 'he did' or 'he didn't): he did 'order' me to do it, but having no authority over me, he couldn't 'order' me: he did warn me it was going to charge, but it wasn't or anymway I knew much more about it than he did, so in a way he couldn't warn me, didn't warn me. We hesitate between 'He didn't order me' and 'He had no right to order me', 'He oughtn't to have said he ordered me', just as we do between 'You didn't know', 'You can't have known', 'You had no right to say you knew' (these perhaps having slightly different nuances, according to what precisely $i$ tis that has gone wrong). But the essential factors are (a) You said you knew; you said you promised (b) You were mistaken; you didn't perfom. The hesitancy concerns only the precise way on which we are to round on the original 'I know' or 'I promise'. 
To suppose that 'I know' is a descriptive phrase is only one (more) example of the descriptive fallacy, so common in philosophy. Even if some language is now purely descriptive, language was not in origin so, and much of it is still not so. Utterance of obvious ritual phrases, in the appropriate circumstances, is not describing the action we are doing, but doing it ('I do') [...] Such phrases cannot, strictly, be lies [...] (p. 102-103).

Neste ponto Austin defende que considerar "I know" como uma expressão descritiva é mais um exemplo da falácia descritiva tão comum em filosofia. Como se sabe, ele procura constantemente combater tal falácia descritiva. No entanto defender que "I know" não é uma expressão descritiva é uma posição particularmente controversa, mesmo para os seus seguidores. Por exemplo Guy Langworth pensa que Austin está completamente errado ${ }^{24}$, e Benjamin McMyler considera que Austin não tinha ainda ideias completamente claras quanto aos instrumentos conceptuais necessários para desenvolver coerentemente o paralelismo entre saber e prometer quando escreve Other Minds ${ }^{25}$. Retomarei a análise de McMyler mais à frente. Quanto a Longworth, ele pensa que dizer, como diz Austin, que I know that $p$ tem uma função performativa e não descritiva é simplesmente falso. I know that $p$ pode perfeitamente ter uma função descritiva: pode perfeitamente haver uma auto-descrição em que alguém diz que sabe que p (I know that p). E, aliás, não é nada claro que função performativa tem Austin em mente quando afirma que I know that $p$ tem uma função performativa. Por outro lado, em casos em que I know that $p$ tem função performativa, nem a falsidade nem a verdade (na obtenção) do que se declara dependem do facto do falante, ele próprio, saber que as coisas são de determinada maneira. Austin se deixaria pois, segundo Longworth, iludir pelas semelhanças entre saber e prometer. A verdade é que ao contrário de "Prometo que p" (por exemplo "Prometo que te pagarei estes 50.000 euros que agora me emprestas"), que institui uma realidade, afirmar

24 Longworth 2015.

25 McMyler 2011. 
"I know that p" não faz com que seja o caso que eu saiba (alguma coisa), não institui essa realidade.

\section{Conclusão de 0ther minds — aplicação às outras mentes de considerações performativas sobre saber}

O ponto de chegada de Other Minds é a aplicação ao caso das outras mentes das considerações performativas sobre conhecimento desenvolvidas ao longo do artigo. Austin afirma desde logo, que discutirá apenas a forma como sabemos que uma outra pessoa está zangada (feelings and emotions) e não os seus pensamentos, ou que viu um rato. A primeira coisa que faz é aplicar a distinção entre knowing e believing: a situação de sabermos que (um homem está zangado) é diferente da situação de acharmos que (um homem está zangado). Em seguida defende que nem por um momento supomos que sabemos isso (que está zangado) de todos os homens, ou de todos os tipos de homens: "The feelings of royalty, or fakirs, or bushmen or Wyckemists, or simple eccentrics - these may be very hard to divine". (p. 104)

Mais ainda do que no caso do pintassilgo, muito depende de quanto no passado tivemos experiência deste indivíduo, ou deste tipo de situação. Se não temos essa familiaridade, hesitamos em dizer que sabemos. Mas, "we certainly can recognize when some near relative is angrier than we have ever seen him" (p. 104).

E como sabemos? Será que devemos seguir Mr. Wisdom e distinguir aqui sintomas de sentimentos, de forma que quando me perguntam “Como é que sabes que ele está zangado?" eu deva responder "Pelos sintomas", enquanto que, se perguntassem a ele, ele diria "pelo sentimento?". Isto parece um simplismo perigoso, diz Austin (p. 105). Desde logo porque estamos a usar "sintomas" de uma forma desviada do uso normal, que é por exemplo o uso médico - aí o termo é usado sobretudo para casos de algo indesejável, como uma doença incipiente. Mas, sobretudo, porque não falamos de sintomas a não ser para fazer um contraste com a inspecção directa da coisa própria - essa divisão é 
suposta existir sempre. "Sintoma" funciona como "rastro" ou "pistas" ou "sinais". Ora, quando se sabe quem é o assassino, já não há mais pistas:

When the cheese is not to be found or seen then there may be traces of it; but not when it's there in front of us [...] (what is wrong with $\mathrm{Mr}$ Wisdom paradox about looking in the larder and 'finding all the signs' of bread, when we see the loaf, touch it, taste it, and so on. Doing these things is not finding (some) signs of bread at all: the taste or feel of bread is not a sign or symptom of bread at all (p. 106).

O que diríamos ao olhar para algo à nossa frente na despensa é que há ali alguma coisa parecida com, ou que parece ser, pão - não diríamos que há sintomas de pão, ou sinais de pão. Analisados tais usos de "sinais" e "sintomas", se torna claro que só falamos de sintomas ou sinais quando não conseguimos chegar à coisa ela própria. Queremos então dizer que sabemos que "a man is angry" pelos sintomas de "anger"? Embora em casos específicos possamos falar de "symptoms of anger", a resposta de Ausitn é negativa: "Symptoms or signs of anger tend to mean signs of rising or of suppressed anger. Once the man has exploded, we talk of something different - of an expression, or manifestation, or display of anger" (p. 107).

Se só tivessemos sintomas, diríamos que pensamos, que achamos, que suspeitamos, que desconfiamos, mas não que sabemos. Acontece que nós somos capazes de mais do que apenas "desconfiar" que um outro homem está zangado: "There is a peculiar and intimate relationship between the emotion and the natural way of venting it. (p. 108) Moreover, there are natural occasions of anger. (p. 109) [...] Being angry is like having mumps - a description of a whole pattern of events (p. 110)."

Estar zangado é como ter papeira - trata-se da descrição de um padrão de eventos que eu sou capaz de reconhecer. E é a nossa confiança em reconhecer o padrão que nos permite dizer que sabemos que uma outra pessoa está zangada. Não se trata de sintomas e de "acharmos", ou "pensarmos que". Até agora as dificuldades que poderíamos ter (por exemplo em provar que uma outra pessoa está zangada) são paralelas ao caso de There is a goldfinch in the garden. No entanto, diz 
Austin, "there is still a feeling, and I think a justified feeling, that there is a further and quite special difficulty in the later case" (p. 111).

Por quê? Porque pareceria que todos os sintomas podem estar presentes e ainda assim o homem poderia não estar zangado (estará a ter outra emoção? nenhuma emoção? - isto é algo que Wisdom pergunta na sua abordagem ao problema das outras mentes). Mas será este caso paralelo ao caso da ilusão quanto a objectos materiais? - é esta a pergunta de Austinn ${ }^{26}$. De acordo com Austin este caso não é paralelo ao caso da ilusão relativa a objectos materiais - este é um ponto essencial do artigo. Qual é então a diferença? Na vida comum preocupamo-nos com saber se alguém nos está a enganar, se o estamos a compreender mal, se o que está a fazer é deliberado ou não. Todas essas dificuldades surgem quanto às acções das pessoas, mesmo aquelas que conhecemos muito bem. Nenhuma destas dificuldades nos surgem com pintassilgos, ou pão, ou oásis ou varas quebradas:

The goldfinch cannot be assumed, nor the bread suppressed: we might be deceived by the appearance of an oasis, or misinterpret the signs of the weather, but the oasis cannot lie to us, and we cannot misunderstand the storm in the way we misunderstand the man (p. 112)

E, finalmente, há uma outra característica do caso das outras mentes que o torna radicalmente diferente do caso do pintassilgo, ou do pão, ou de oásis ou varas quebradas:

${ }^{26}$ Este é um ponto de convergência nítida com Wittgenstein (a forma de colocar a questão, não a resposta). De qualquer forma, do ponto de vista da história da filosofia, Austin não está sozinho ao defender que o nosso conhecimento da mente de outrem não envolve inferência a partir de sintomas — Wittgenstein defende algo semelhante (não apenas Wittgenstein: cf. Avramides 2001 para uma visão histórica panorâmica do problema das outras mentes) Se considerarmos Wittgenstein e Austin como os dois grandes representantes da filosofia da linguagem comum, concluímos então que a posição maioritária na filosofia da linguagem comum acerca de outras mentes é uma posição não inferencialista. No entanto Wittgenstein baseia a sua própria posição em considerações sobre percepção enquanto que as considerações de Austin são sobre performatividade. A interpretação que por exemplo John McDowell faz das origens wittgensteinianas do disjuntivismo (acerca de percepção e de conhecimento) explora o paralelismo entre fingimento e ilusão, e portanto entre o conhecimento as outras mentes e 0 conhecimento de objectos (cf. Miguens, no prelo "The ever-present temptation of answering the skeptic - John McDowell's and Stanley (avell's wittgensteinianism"). Em Austin, em contraste, a relação com as outras mentes não sendo inferencial não é tão pouco tratada como perceptiva.

Rev. Filos., Aurora, Curitiba, v. 28, n. 44, p. 653-686, maio/ago. 2016 
The goldfinch, the material object, is, as we insisted above, uninscribed and mute: but the man speaks. In the complex of occurrences which induces us to say we know another man is angry, the complex of syptoms, occasions, display, and the rest, a peculiar place is occupied by the man's own statement as to what his feelings are (p. 113).

Os homens falam, e quando se trata do conhecimento de outras mentes, nós damos atenção particular ao que eles dizem "acerca do seu interior". E, precisamente, (poderíamos até resumir desta forma o ponto de Austin) a statement is not a symptom: uma asserção ou enunciação não é um sintoma. Não tratamos como sintomas as enunciações dos outros homens acerca do seu "interior". Essa é uma diferença incontornável relativamente a "objectos materiais" 27 e um aspecto crucial para o problema das outras mentes. Resta uma questão: por que é que havemos de acreditar no que as pessoas nos dizem, por que havemos de acreditar nas suas asserções? Para Austin tal questão "faz parte" do problema das outras mentes e a sua resposta é que acreditar nas outras pessoas, na autoridade e no testemunho, é simplesmente uma parte essencial do acto de comunicar, um acto que constantemente praticamos. Acreditar nas outras pessoas é uma parte irredutível da nossa experiência, como fazer promessas ou jogar jogos de competição, ou percepcionar cores. Podemos falar de vantagens de tal performance, podemos explicitar e elaborar as suas regras, mas a verdade é que não há justificação nenhuma para as coisas serem assim - elas são assim. É com estas declarações que Austin termina Other Minds (p. 115). Olho em seguida para aquilo que me parece ser um ponto de aplicação por excelência das considerações austinianas sobre outras mentes e sobre o estatuto daquilo que as outras pessoas nos dizem: a questão epistemológica do testemunho.

${ }^{27}$ Note-se que em Sense and Sensibilia Austin se rebela contra esta expressão, que considera receber o seu estatuto de uma função artificial de contraste com sense data. 


\section{As teses de McMyler sobre Austin sobre testemunho}

Em "Believing What the Man Says About His Own Feelings" (um título directamente retirado de Other Minds, p. 114) ${ }^{28}$ Benjamin McMyler procura precisar as parcas observações de Austin sobre testemunho em Other Minds tornando-as numa posição sustentável. A sua intenção é rejeitar a interpretação usual de tais observações, de acordo com as quais Austin veria o conhecimento como um acto de fala. As teses de McMyler são as seguintes:

a) A ligação entre testemunho e acto de fala não é directa. O que Austin afirma sobre testemunho em Other Minds, na secção If I know I can't be wrong, foi muito frequentemente mal interpretado. Saber alguma coisa, i.e. ter conhecimento de que p, por exemplo, saber que está um pintassilgo no jardim, não é em si ou por si um acto de fala; é de facto preferível dizer que saber que p é um "estado"29. No entanto quando alguém diz, por exemplo, que "Mendeleev, Lenine e Pavlov estudaram, todos eles, na Universidade de São Petersburgo" perante outra pessoa, o dizê-lo, o acontecer da asserção, é, aí sim, um acto de fala. É esse acto de fala que McMyler considera ser um acto de fala de testemunho.

b) Quando alguém diz a outrém "I know that p" ("Eu sei que p") essa pessoa não está a fazer uma atribuição de crença a si própria mas sim a fazer algo diferente. Mcyler propõe que neste caso trata-se de um acto de fala de testemunho, no qual (como no acto de fala de prometer) se trata de dar a nossa palavra.

Austin, ele próprio hesitaria em fazer a identificação que McMyler faz entre "I know that $p$ " e o acto de fala de testemunhar, e isso constitui obviamente um problema. $\mathrm{O}$ problema relaciona-se com a prática metodológica de Austin, com o facto

28 McMyler 2011.

29 Por exemplo T. Williamson (e isto é essencial na sua knowledge-first epistemology) defende que saber que p é um estado, e que é factivo. 
de ele individuar actos de fala apoiando-se apenas na existência de expressões linguísticas particulares. McMyler admite que esta prática não ajuda a clareza da discussão austiniana da analogia entre saber e prometer.

c) O propósito da analogia austiniana entre saber e prometer é estabelecer que vir a saber que $p$ com base no testemunho pressupõe acreditar no falante que afirma que $p$. Quer prometer quer testemunhar supõem um salto para além do mero declarar de uma intenção ou de uma crença. Em ambos os casos se trata do falante dar a sua palavra, ligando-se assim com outra pessoa. No caso da promessa, o falante compromete-se a procurar fazer com que venha a ser o caso que p. Ora, é obviamente perante outrem que o falante se compromete. Por contraste uma intenção declarada poderia perfeitamente ser só do falante. No acto de fala de testemunho, o falante também se compromete perante outrem, não se limita a declarar que tem uma crença determinada. $\mathrm{O}$ falante põe a sua audiência em contacto epistémico com p, é responsável pelas credenciais epistemológicas da crença que o ouvinte venha a fixar. Em ambos os casos - prometer, testemunhar - a diferença (relativamente a declarar uma intenção, ou declarar uma crença) está, assim, na relação com os outros envolvidas nesses actos, estando em ambos os casos envolvida a responsabilidade do falante.

Evidentemente as descrições acima não se aplicam necessariamente a todas as enunciações linguísticas feitas por alguém, desde logo porque nem tudo o que é dito por falantes, quando estes fazem asserções, é proposto para ser acreditado (da mesma maneira). O contraexemplo mais imediato é o caso de um actor num palco, representando um personagem, fazendo afirmações (por exemplo Othelo fazendo afirmações acerca das acções de Desdémona). Neste caso o que é dito não é (em princípio) dito para ser acreditado pelo público que assiste à peça (pelo menos não da mesma maneira que no caso em que eu digo numa aula "Mendeleev, Lenine e Pavlov estudaram, todos eles, na Universidade de São Petersburgo"). Por outro lado, há certamente 
casos em que o falante não acredita naquilo que assere, mas pode ser acreditado por quem o ouve. Imaginemos uma professora de Biologia americana que é criacionista, mas que ensina aos alunos os princípios da teoria da evolução, porque o seu emprego a obriga a isso ${ }^{30}$. Será que os seus alunos podem aprender com ela esses princípios, i.e. os conteúdos asseridos mas não acreditados pelo falante? Diríamos que sim. Como havemos de conceber a situação no quadro da posição austiniana tal como esta é especificada por McMyler? Questões como estas requerem ajustes na posição de Austin, tal como esta é especificada por McMyler ${ }^{31}$. Podemos aceitar, no entanto, que tais ajustes seriam possíveis.

\section{Conclusão}

Saímos de Other Minds não apenas com uma proposta quanto ao que sabemos quando sabemos alguma coisa, mas também com uma sugestão crucial quanto ao problema das outras mentes. A sugestão é que a nossa relação epistemológica com outras mentes é muito diferente da nossa percepção de objectos, sejam estes pintassilgos, varas dobradas, miragens, ou espelhos ${ }^{32}$. Desde logo, as nossas preocupações quando se trata do conhecimento de outras mentes são completamente diferentes: quando se trata de outras mentes nos preocupamos com o fingimento, com tentativas de enganar-nos, com a (nossa) possível má compreensão, com a presença ou ausência de intenção deliberada (de outrem) de fazer algo. Pintassilgos, varas dobradas, miragens, ou espelhos não fingem nem nos enganam, não são dissimulados nem nos manipulam: quando os percepcionamos nos preocupamos com ilusões, eventualmente com delírios e alucinações, mas não com fenómenos dessa ordem. É esta distinção que Austin pretende estabelecer, com

30 Cf. O'Brien (2013: 121).

${ }^{31}$ Como afirmei no início do artigo, as questões da verdade e do acto (e de tipos de actos) tratadas por F. Récanati e C. Travis nas sessões anteriores do Ciclo Austin são essenciais aqui. Neste ponto específico torna-se necessário distinguir"tipos de acto"e casos distintos quanto à força de um acto.

32 Listo exemplos de Other Minds e Sense and Sensibilia. 
aquela que me parece ser a frase-chave de Other Minds: The goldfinch is mute; the man speaks.

Os homens falam e é também o estatuto epistemológico daquilo que os outros nos dizem (i.e. a natureza do conhecimento por testemunho) que interessa particularmente Austin no artigo. $\mathrm{O}$ conhecimento por testemunho envolve fenômenos que estão simplesmente ausentes do nosso conhecimento perceptivo de objectos, tais como o pintassilgo ou a vara dobrada - envolve fenômenos como a confiança (no falante), a autoridade e a responsabilidade (do falante). No cruzamento das abordagens das outras mentes e do testemunho, há assim uma conclusão que ressalta: num sentido importante, o problema das outras mentes é para Austin um problema de segunda pessoa, e não um problema de terceira pessoa ${ }^{33}$. Só pensaremos que o problema das outras mentes se coloca em terceira pessoa, i.e. como um problema acerca da imputação de uma interioridade a uma exterioridade, em tudo semelhante à exterioridade do pintassilgo, da vara ou do espelho, se não formos capazes de apreciar o papel fundamental que a confiança, o acreditar nas outras pessoas, tem nas nossas vidas. O que está em causa no conhecimento por testemunho (acreditar em alguém) é pôr-se nas mãos dessa pessoa em que acreditamos, lhe atribuir responsabilidade pelo nosso conhecimento. Isto é algo de muito diferente da imputação de mentalidade por mindreading, e abre de resto espaço para um tipo de abuso (fingimento, manipulação, mentira, etc), que só podemos sofrer de outras pessoas, não das coisas inanimadas do mundo, como pintassilgos ou espelhos ${ }^{34}$.

O que pensaria, então, Austin perante o actualmente muito difundido tratamento do problema das outras mentes como um problema de terceira pessoa (muito claro, por exemplo, quando nos afeiçoamos aos zombies da actual filosofia da mente e aos argumentos anexos)? Pensaria certamente que a nossa prontidão em aceitar esse tipo de argumentos mostra que não reconhecemos o papel fundamental que a confiança tem nas práticas humanas.

33 McMyler 2011: 137.

34 McMyler 2011: 138. 
E o que pensaria Austin da visão reducionista dominante hoje na epistemologia do testemunho, que nos faz ver o problema da epistemologia do testemunho como um problema relativo a considerações sobre a fiabilidade de outra pessoa, sendo essa fiabilidade avaliada por nós próprios, a partir da evidência disponível? Como é frequentemente o caso na filosofia da linguagem comum perante problemas filosóficos vários, Austin diria talvez que é uma distorção da nossa prática comum de acreditar nas outras pessoas, uma convicção injustificadamente intelectualista, que ignora o facto de a second-person perspective, a perspectiva de segunda pessoa, com as questões de autoridade e responsabilidade que lhe são inerentes, ser non-optional (ela não é uma opção aqui - i.e. não podemos escapalhar-lhe $)^{35}$.

Para voltarmos às referências clássicas enquadradoras da epistemologia do testemunho, Austin está próximo de Thomas Reid e distante de David Hume: acreditar nas outras pessoas é algo que fazemos constantemente "sem que haja uma justificação específica para o fazermos." Por mais dogmática que possa parecer a afirmação, ela tem por trás um ponto extremamente importante. Austin não está a exprimir uma ingenuidade psicológica beatífica: não está a dizer que, na nossa vida quotidiana, devemos, submissa e acriticamente, acreditar naquilo que as outras pessoas nos dizem. O que está em causa é, de alguma forma, prévio: trata-se de conceber a forma como nós estamos perante as asserções linguísticas das outras pessoas numa situação em que nós, os humanos, estamos unidos pela linguagem, de uma forma que é anterior à busca explícita de razões e de justificações para crenças específicas e, portanto, anterior ao campo da epistemologia propriamente dita. De acordo com Austin, quando estamos perante asserções de outras pessoas não estamos perante evidência, sinais ou sintomas, que do alto da nossa suficiência epistemológica avaliamos como provas. Acreditar nas outras pessoas e naquilo que elas nos dizem é antes algo como uma condição da forma humana de conhecer: "[...] believing in other persons, in authority and testimony, is an essential part of the act of communicating, an act which we all constantly perform" (p. 115).

35 McMyler 2011: 142. 
O que tudo isto tem a ver com o realismo de Oxford? Procurei identificar com o perfil que tracei no início do artigo, as teses do próprio Austin, definidas não apenas em Other Minds, mas também em Sense and Sensibilia. Penso ter ilustrado esse perfil com a leitura próxima do texto de Other Minds. Evidentemente não encontramos todas as teses que listei em todos os "realistas de Oxford", desde Cook Wilson e Pritchard, até McDowell e Williamson, Snowdon ou Travis. Na verdade, do ponto de vista da história do realismo de Oxford, Austin é particularmente importante precisamente por ter acompanhado as teses quanto a percepção e conhecimento (que se encontram em autores anteriores como Cook Wilson e Pritchard, que não são filósofos da linguagem sofisticados) ${ }^{36}$ numa tematização metodológica explícita, em torno da linguagem comum. A concepção austiniana do papel da linguagem comum traduz-se numa visão do método para a filosofia. Austin é também especialmente importante por ter acompanhado as teses quanto a percepção e conhecimento com elaboradas concepções de verdade, factos e acção. Embora tais concepções não tenham sido aqui directamente consideradas, são elas que sustentam as suas posições. No entanto algumas das convicções fundamentais de Austin são comuns a muitos dos realistas de Oxford. É este o caso, por exemplo, das concepções de percepção e conhecimento como sendo não híbridos (de algo de mental a que se acrescenta algo de não-mental), mas sim básicos. É o caso da assimetria entre os bons e os maus casos (na percepção, no conhecimento): quer na percepção, quer no conhecimento pode haver falhas, pode haver maus funcionamentos, mas isso não invalida que o caso por defeito seja o caso em que percepcionamos ou conhecemos de facto as formas como as coisas são. É o caso ainda da rejeição de uma concepção de aparências como "meras aparências" e o correlativo trabalho com a noção de apareceres objectivos intersubjetivamente partilhados. É o caso da ideia segundo a qual não há nenhum estatuto especial do conhecimento do "interior". É finalmente a convicção de que o realismo ingénuo sobrevive às formas várias do argumento da ilusão em operação na filosofia contemporânea. E bastam esses pontos

36 Cf. Travis e Kalderon 2013. 
para o realismo de Oxford fazer uma enorme diferença nas mais variadas discussões actualmente em curso na filosofia.

\section{Referências}

ADLER, J. "Epistemological problems of testimony". The stanford encyclopedia of Philosophy (Summer 2015 Edition), Edward N. Zalta (Ed.). Disponível em: $<$ http://plato.stanford.edu/archives/sum2015/entries/testimony-episprob/>.

AUSTIN, J. L. “Other Minds”. In: Philosophical papers. Oxford: Oxford University Press p. 76-116. Inicialmente publicado em: Proceedings of the Aristotelian society (Supplementary Volume, 20). Simpósio: p. 122-197. Artigo de Austin no Simpósio: p. 148-187, 1961a/1946.

AUSTIN, J. L. Philosophical papers. Oxford: Oxford University Press, 1961.

AUSTIN, J. L. Sense and sensibilia. Oxford: Oxford University Press, 1962.

CRANE, T.; FRENCH, C. "The problem of perception". The stanford encyclopedia of Philosophy (Spring 2016 Edition). Edward N. Zalta (ed.), 2016. Disponível em: <http://plato.stanford.edu/archives/spr2016/entries/perception-problem>.

LONGWORTH, G. "John Langshaw Austin", The stanford encyclopedia of Philosophy (Summer 2015 Edition), Edward N. Zalta (ed.), 2015. Disponível em: $<$ http://plato.stanford.edu/archives/sum2015/entries/austin-jl/>

AVRAMIDES, A. Other Minds. London: Routledge, 2001.

MCMYLER, B. "Believing what a man says about his own feelings". In: GUSTAFSSON, M.; SORLI, R. (Orgs.) The Philosophy of J. L. Austin. Oxford, Oxford University Press, 2011, p. 114-145.

MIGUENS, S. "O comum, o manifesto e o óbvio - os filósofos analíticos e a linguagem". In: MAURO, C.; MIGUENS, S.; CADILHA, S. (Coord.) Mente, linguagem e acção, Porto: Campo das Letras, 2009, p. 227-250. 
MIGUENS, S. "The ever-present temptation of answering the skeptic - John McDowell's and Stanley Cavell's wittgensteinianism". In: ROMÃO, R. B.; MARQUES, A. (Org). Wittgenstein and the Skeptic Tradition. Bern: Peter Lang. (No prelo).

MIGUENS, S. A estranheza do comum. Recensão crítica à tradução portuguesa de L. Wittgenstein. Observações sobre o Ramo Dourado de Frazer. Revista da Faculdade de Letras - série de Filosofia, 27-28, p. 248-251, 2010-2011.

O'BRIEN, D. Introdução à teoria do conhecimento. Lisboa: Gradiva, 2013.

SOTERIOU, M. "The disjunctive theory of perception", The Stanford encyclopedia of Philosophy (Summer 2014 Edition), Edward N. Zalta (Ed.), 2014. Disponível em: <http://plato.stanford.edu/archives/sum2014/entries/perception -disjunctive/>

TRAVIS, C. "The silence of the senses", Mind, v. 113, n. 449, p. 59-94, 2004. Tradução portuguesa de S. Miguens e J. Lemos. In: MIGUENS, S.; TELES, M. (Coord.). Aparência e realidade. Lisboa: Colibri, p. 183-233, 2010.

TRAVIS, C.; KALDERON, M. “Oxford realism”. In: M. Beaney ed, The Oxford handbook of the history of analytic Philosophy. Oxford: Oxford University Press. p. 489-517, 2013.

Recebido: 20/11/2015

Received: 11/20/2015

Aprovado: $14 / 02 / 2016$

Approved: 02/14/2016 